\title{
The Perception of Dental Practitioners on Laboratory Management for Effective Dental Health Care Delivery: A Case Study of Some Selected Dental Laboratories in Lagos State, Nigeria
}

\author{
Christian Ugwuda ${ }^{1}$, Adegbite A Ayoade ${ }^{2}$ \\ ${ }^{1}$ Head of Department, Department of Dental Technology, Ogun State College of Health Technology, NIGERIA \\ ${ }^{2}$ Head of Department, Department of Water Resources Management and Sanitation, Ogun State College of Health Technology, NIGERIA
}

\begin{abstract}
Objective: The objective of the study was to assess the management of dental laboratory as it significantly affects effective handling of dental problems among dental patients visiting Dental Hospitals/Centres and consequently for effective dental healthcare delivery system in Lagos State as a case study.

Methodology: One hundred (100) dental professionals working in the selected twenty (20) dental hospital/centres across the study area were selected surveyed through a purposive sampling technique. The research instruments used for study were self-opinionated questionnaires and Strength, Weakness, Opportunities and Threat SWOT analysis.

Finding: The results showed that state of the laboratories need to be improved in order to meet current global standards of digital state of equipments, then management of the laboratory with the perception of the staff influence the quality of dental care services given to the patients. The SWOT analysis indicated that opportunities within the profession is the adequacy of training and professionalism, while danger of quack workers, obsolete equipment, erratic power supply to run the equipment and lack of government enabling environment are threat and weakness that affect the dental laboratory activities. The study concluded that state of dental laboratory still need more improvement with the use of modern and digital equipments, and the workers re-training are the strengths and opportunities.Therefore, there is need for workshop, conferences and to educate the professional on the latest equipment in the markets on a global level. Then, the Government should embark on infrastructural development of the existing governmental dental facilities and encourage the private ones.
\end{abstract}

Key words: Dental, Laboratory, Health Care Delivery, Nigeria and Perception

How to Cite: Ugwuda C and Ayoade AA. 2015. The Perception of Dental Practitioners on Laboratory Management for Effective Dental Health Care Delivery: A Case Study of Some Selected Dental Laboratories in Lagos State, Nigeria Malaysian Journal of Medical and Biological Research, 2(2), 49-54.

This article is is licensed under a Creative Commons Attribution-NonCommercial 4.0 International License.

Attribution-NonCommercial (CC BY-NC) license lets others remix, tweak, and build upon work non-commercially, and although the new works must also

acknowledge \& be non-commercial.

\section{INTRODUCTION}

According to online resources, dental technology is the aspect of dental health care delivery which deals with the art and science of designing, fabrication and servicing of dental, oral and oral-facial appliances for the replacement of missing part of dental and oral-facial tissue in order to restore pathologically or surgically lost oro-facial tissues (K.H.T, 1957), (Kent, Homsy and Hinds, 1975), (Cousin, 1997) and (A new oral health care system, 2006). It is also known to be a technical aspect of dentistry where dental technologist make appliances to improve patients' appearance, Invariably, Dental technologists play very crucial part of the dental professional tea, using their understanding of dental material science, and their skills of design and fabrication to recreate people's oral facial tissues (Dean, 2009) and (den-tech4, 2014).

Furthermore, according to (Balenseifen and Madonia, 1970), (Schlott, 2009), (BS, 2013) among others stated that the Dental Technology as a field of study comprises four major divisions but interrelated areas with the ultimate aim of producing protheses worn by dental patients. Moreover, the goal of dental technology is to restore the oral-facial functions of mastication, speech, and aesthetics while preventing over-eruption of opposing teeth and the drifting of adjacent ones (Dubner, Sessle and Storey, 1978) and (Parashar et al., 2005) among others. These activities of dental technologists highlighted above require a functional, well equipped laboratory and qualified laboratory technician/assistant to handle the tools, manage and maintain the laboratory as a result there can be an effective Dental Health Care Delivery (Heffron, 1973), (Harris, 1973), (Prosthetics, 1959), and (Laboratory Reference Values, 2009). 
Unfortunately, in the developing countries Nigeria inclusive, healthcare delivery system including dental health services do experience challenges of manpower, infrastructures, funding, government policies, and unwillingness of some medical professions to adopt technology and the limitation of their experiences and public perception of our healthcare delivery system among others (Nelson, 1990), ('Dental Care Delivery System', 2008), ('Healthcare Information System', 2008), (Moen and Meredith, 2010) and (Seggie, 2012). They believed that the issues mentioned above have been challenges for development of dental healthcare delivery system. Then, in the recent past years, the importance of oral health as an integral part of general health has been the subject of interest and body of evidence linking oral health status (Kieffer and Hoogstraten, 2008), (Nigerian Medical Association, 2010) and (Ghimire, 2013). However, the management of dental laboratory as a hub for effectiveness and efficiency of dental health care delivery system, require functional and operational laboratory with qualified and well-motivated staffs which have been problems in Nigeria healthcare system that experiences brain-drain, lack of infrastructures, obsolete equipments. In dental health service or profession, the provisions of adequate equipment and laboratory are crucial to promote and sustain the field of medical profession-management and organization of dental laboratory for effective dental service is indispensable (Rowell, 1963), (Tepper, 2008), (Bailit, 1990) and (Ghimire, 2013). Therefore, there is need for assessment of dental laboratories as one of the components for development of dental healthcare system efficiency and effectiveness in Nigeria. These are the drive for the study to assess the dental laboratory facilities/centres using Lagos State as case study.

\section{The Broad Objectives of the study}

The objective of the study is to assess the effect of dental laboratory for effective handling and control of dental problems among dental patients in selected Dental facilities/Centres in Lagos State.

\section{Specific Objectives}

The following are the specific objectives of the study are as follows:

(a) To assess the state of laboratory equipment for dental health services in the study area

(b) To assess the extent of the laboratory management as it affect the quality of dental health services and;

(c) To assess strength, weakness, opportunities and threat (SWOT) of the dental laboratories services for the effectiveness of dental healthcare delivery system in the study area.

\section{Research Hypotheses for the study}

The following hypotheses were tested in the course of the study:

(a) $\mathrm{H}_{\mathrm{o}^{-}}$The statuses of the laboratory facilities will not significantly influence dental healthcare delivery system in the study area.

$\mathrm{H}_{\mathrm{a}}$ - The statuses of the laboratory facilities will significantly influence dental healthcare delivery system in the study area.

(b) $\mathrm{H}_{\mathrm{o}}$-The management of the laboratory will not significantly influence dental healthcare delivery system.

$\mathrm{H}_{\mathrm{a}}$-The management of the laboratory will significantly influence dental healthcare delivery system.

\section{The Study area}

The State is composed of the old Federal Territory of Lagos which remains the financial hub and was the Federal Capital of Nigeria (up to December 12, 1991), and the old Colony Province of the defunct Western Region of Nigeria comprising Badagry, Ikeja, Ikorodu and Epe Divisions.

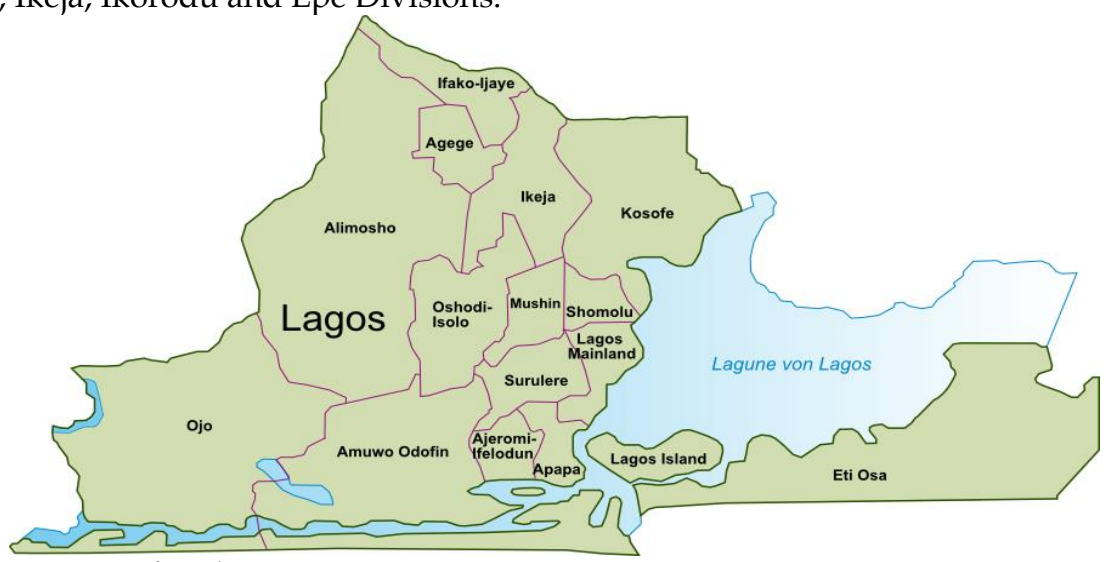

Source: (Wikipedia.org, 2014) Map of Study Area

Situated in the southwestern corner of the country, this elongated state spans the Guinea coast of the Atlantic Ocean for over $180 \mathrm{~km}$., from the Republic of Benin on the west to its boundary with Ogun state in the east. It extends approximately 
from latitude $6^{\circ} 2^{\prime}$ north to $6^{\circ} 4^{\prime}$ north, and from longitude $2^{\circ} 45^{\prime}$ east to $4^{\circ} 20^{\prime}$ east. Of its total area of $3,577 \mathrm{sq}$. km., about 787sq. km. or 22 percent is water (OnlineNigeria.com, 2014) and (Lagos State Bureau of Statistics, 2005).

Furthermore, according to Healthcare Facilities Monitoring and Accreditation Agency (HEFAMAA), of Lagos State Ministry of Health had the following number of registered health facilities: (a) 26 General Hospitals, (b) 256 Public Healthcare Centers, (c) 2,886 Private Hospitals/Clinics/Laboratories/Ophthalmic/Dental/Diagnostic Centers and (d) Estimated 160 Trado-Medical Centers. Out of these facilities, there are fifty seven (57) are registered dental clinics LAWMA (2014).

\section{Methods and Materials}

The participants for the study include one hundred (100) dental professionals working in the selected twenty (20) dental clinics/centres across the study area out of registered fifty seven dental clinics. They were selected through a purposive sampling technique. The research instruments used for study were self-opinionated questionnaires and SWOT form adapted to the respondents.

\section{The self-opinionated questionnaires administration Instrument}

The self opinionated administered questionnaires were designed with 5-item Likert scale, where respondents were asked to indicate the degree to which they agree and disagree with the opinion expressed by the statements in the questionnaires. The agreements with positively worded statements are assigned higher scores. The first sets of statement are positively phrased; agreement indicates a favourable attitude toward the relevance of management of laboratories and Effective Dental Health Care Delivery. The second sets of statement are negatively worded, and so the scoring is reversed- a 1 is assigned to those who strongly agree, and so forth. This reversal is necessary so that a high score will consistently reflect positive attitudes towards relevance of management of dental laboratories and effective Dental Health Care Delivery. The summation features of Likert scales make it possible to make distinct differences among people with different viewpoints (Loiselle, et al., 2004).

The questionnaire consists of two sections. The Section A, sought general information on Demography characteristics of the respondents and Section B contains six statements on relevance of dental laboratories and effective dental health care delivery as identified above (Adapted from Loiselle, et al., 2004). The copy of questionnaires were given out to the respondents and retrieved on the spot after they have been completed.

\section{The SWOT analysis Instrument}

Then, a SWOT analysis is adapted-a structured planning method used to evaluate the strengths, weaknesses, opportunities and threats involved in 'management of the dental laboratories' (Wikipedia, 2014).The name says it: Strength, Weakness, Opportunity, Threat. A SWOT analysis guides someone to identify the positives and negatives inside an organization (S-W) and outside of it, in the external environment (O-T). Developing a full awareness of your situation can help with both strategic planning and decision-making. A SWOT analysis can be carried out for a product, place, industry or person. It involves specifying the objective of the business venture or project and identifying the internal and external factors that are favourable and unfavourable to achieve that objective (Community Tool Box, 2014).

Therefore, the SWOT Analysis was employed for understanding the Strengths and Weaknesses, and for identifying both the Opportunities open to and the Threats facing the dental laboratories that can influence the effectiveness of dental healthcare delivery in the study area in particular and Nigeria in general.

\section{RESULTS AND DISCUSSION}

\section{Result of Demography characteristics of the respondents}

Out of Twenty (20) dental facilities/centres visited and one hundred (100) respondents took part in the study, ten (10) respondents each from the facilities/centres. The result showed that sixty (60) $60 \%$ of the respondents were male, while the rest forty (40) $(40 \%)$ were female (See table 1 below).

Table I: Showing the demographics characteristics of the respondents

\begin{tabular}{|l|l|l|c|c|c|l|c|c|}
\hline Sex & \multicolumn{3}{|c|}{ Years of Experiences } & \multicolumn{3}{|c|}{ Education/Qualification } \\
\hline & No & $\%$ & & No & $\%$ & & No & $\%$ \\
\hline Male & 60 & 60 & $1-3$ & 23 & 23 & Postgraduate & 12 & 12 \\
\hline Female & 40 & 40 & $4-6$ & 65 & 65 & Graduate & 83 & 83 \\
\hline & & & $>7$ & 12 & 12 & Secondary & 5 & 5 \\
\hline Total & $\mathbf{4 0}$ & $\mathbf{6 0}$ & & $\mathbf{1 0 0}$ & $\mathbf{1 0 0}$ & & $\mathbf{1 0 0}$ & $\mathbf{1 0 0}$ \\
\hline
\end{tabular}

The results as started in the table 1 above show the years of experiences of the respondents. Twenty three (23) have spent between 1-3 years working in dental facilities/centres; the majority of the respondents sixty five (65) have between 4-6 years of experiences and the least number of respondents twelve (12) have put in more seven (7) years of service in the dental facilities/centres. On the hands, the educational/qualification distribution of the 
respondents showed that twelve (12) hold postgraduate certificate, eight three (83) are graduates holding either BSc and HND certificates with a few number of the respondents five (5) are school certificate holders.

The distribution of educational/qualifications status and years of experiences of the respondents indicated that the responses obtained can be reliable upon to for the analysis and might be used to generalize the situation.

\section{Responses on Questionnaires- Positive and Negative Statements}

Table II: Showing the scores of the positive and negative statements of the respondents

\begin{tabular}{|c|c|c|c|c|c|c|c|c|}
\hline & & \multicolumn{5}{|c|}{ Number of Responses } & \multicolumn{2}{|c|}{ Score } \\
\hline & & SA & A & $?$ & D & SD & + & - \\
\hline 1 & The state of Laboratory facilities influence dental healthcare delivery systems* & 54 & & & & & 270 & \\
\hline 2 & The Laboratory management influence dental healthcare delivery system* & & 75 & & & & 300 & \\
\hline 3 & The attitudes of Laboratory workers influence dental healthcare delivery system* & & & 3 & & & 9 & \\
\hline 4 & $\begin{array}{l}\text { The State of Laboratory facilities do not necessarily influence dental healthcare } \\
\text { delivery system** }\end{array}$ & & & & & 23 & & 115 \\
\hline 5 & The Laboratory management will not influence dental healthcare delivery system ${ }^{* *}$ & & & & 21 & & & 84 \\
\hline 6 & $\begin{array}{l}\text { The attitudes of Laboratory workers do not influence dental healthcare delivery } \\
\text { system }^{* *}\end{array}$ & & & 2 & & & & 6 \\
\hline & TOTAL SCORE & & & & & & 579 & 205 \\
\hline
\end{tabular}

The method was adapted from Loiselle, C, G et al., (2004). *Positive statement ${ }^{* *}$ Negative statement strongly agreed (SA), Agreed (A), No Idea (?), Disagreed (D), Strongly Disagreed (SD)

The table 2 above displayed the responses of the respondents surveyed on their perceptions of 'the state of Laboratory facilities influencing dental healthcare delivery systems', 'the laboratory management do influence dental healthcare delivery system' and 'the attitudes of laboratory workers can influence dental healthcare delivery system'. The responses to the positive statements showed that out one hundred respondents, fifty four (54) strongly agreed that the state of Laboratory facilities influencing dental healthcare delivery systems, seventy five (75) agreed that the ways dental laboratory are managed influence dental healthcare delivery system, while three (3) were not sure if the attitudes of laboratory workers can influence the dental healthcare delivery system.

On the other hands, twenty three (23) strongly disagreed that, the state of laboratory facilities do not necessarily influence dental healthcare delivery system, twenty one (21) disagreed that the laboratory management will not influence dental healthcare delivery system, while two(2) not sure if the attitudes of laboratory workers do not influence dental healthcare delivery system.

The interpretation of the positive and negative statements is determined by summing the scores. The positive scores of five hundred and seventy nine (579) an indication on positive attitude and understanding the implications of state of laboratory and good laboratory management among dental professional and practitioners for effectiveness of dental healthcare delivery system while the total negatives scores of two hundred and five (205) less than that of positive statement, expressing the the nonchalant attitudes of some of the respondents to management of dental laboratory as state of the laboratory do not have any impact on dental healthcare delivery system.

Though, some of the facilities/centres visited have standard laboratories for the practice the dental services with modern equipments. But the constant power supply to operate some of the equipment is always issues that need to be addressed and dental healthcare delivery system can be affected.

\section{Results of the Test of Hypotheses for the Study}

The states of the Laboratory facilities will not significantly influence dental healthcare delivery system.

Table III: showing the testing of hypothesis on the state of the laboratory

\begin{tabular}{|l|c|c|c|c|c|}
\hline & Observed (O) & Expected (E) & O-E & $\mathbf{( O - E ) ~}^{\mathbf{2}}$ & $\frac{(\mathbf{O}-\mathbf{E}) \mathbf{2}}{\mathbf{E}}$ \\
\hline Strongly Agreed & 54 & 25 & 29 & 841 & 33.64 \\
\hline Agreed & 13 & 25 & -12 & 144 & 5.76 \\
\hline Disagree & 10 & 25 & -15 & 225 & 9 \\
\hline Strongly Disagreed & 23 & 25 & -2 & 4 & 0.16 \\
\hline Total & $\mathbf{1 0 0}$ & $\mathbf{1 0 0}$ & & & $\mathbf{4 8 . 5 6}$ \\
\hline
\end{tabular}

The given equation $\chi^{2}=\sum \frac{(O-E)^{2}}{E}$

The given equation $\quad$, is used to calculate the chi-square to perception or the understanding of the respondents on the subject matter. From the calculation as shown in the table 3 above, the calculated summation of $x^{2}$ (48.56) is greater than 7.82 at 0.05 level of significance with 3 degree of freedom. The null 
hypothesis set for the study area should be rejected. That is the statuses of the Laboratory facilities will not significantly influence dental healthcare delivery system should be rejected. The respondents believed that the conditions and facilities of a dental laboratory can affect the jobs of the dental practitioners and consequently affect the dental health services render to patients.

The management of the Laboratory will not significantly influence dental healthcare delivery system.

Table IV: showing the testing of hypothesis on management of the Laboratory

\begin{tabular}{|l|c|c|c|c|c|}
\hline & Observed (O) & Expected (E) & O-E & $\mathbf{( O - E ) ~}^{\mathbf{2}}$ & $\frac{(\mathbf{O}-\mathbf{E}) \mathbf{2}}{\mathbf{E}}$ \\
\hline Strongly Agreed & 2 & 25 & -25 & 529 & 21.16 \\
\hline Agreed & 75 & 25 & 50 & 2500 & 100 \\
\hline Disagreed & 21 & 25 & -4 & 16 & 0.64 \\
\hline Strongly Disagreed & 2 & 25 & -23 & 529 & 21.16 \\
\hline Total & $\mathbf{1 0 0}$ & $\mathbf{1 0 0}$ & & & $\mathbf{1 4 2 . 9 6}$ \\
\hline
\end{tabular}

Similarly, the calculated, $x^{2}$ values of 142.96 is greater than 7.82 at 0.05 level of significance, with 3 degree of freedom. The second null hypothesis for the study should also be rejected- the management of the Laboratory will not significantly influence dental healthcare delivery system. In other words, management of dental laboratory with provision of qualified dental profession/practitioner influence and promote dental healthcare delivery systems.

The responses on SWOT form

Table V: showing the responses on SWOT on the dental Laboratory for effective Dental Healthcare Delivery System

\begin{tabular}{|l|l|}
\hline Strength & Weakness \\
\hline -Efficient of Dental Professional Bodies/Council & $\begin{array}{l}\text {-Unavailability of constant power supply } \\
\text {-Lack of Government Policies }\end{array}$ \\
\hline Opportunities & Threat \\
\hline -Curriculum of Dental Course & $\begin{array}{l}\text {-Quack workers in the profession } \\
\text {-Training }\end{array}$ \\
$\begin{array}{l}\text {-Obsolete equipments } \\
\text {-Dependent on foreign equipments and importation of materials } \\
\text { Low patronage due perception of people on dental healthcare }\end{array}$ \\
\hline
\end{tabular}

The table 4 above, showed the responses on the strength, weakness, opportunities and threat of dental laboratories for effective dental healthcare management. The most appeared submissions are displayed in each box. The respondents believed that the professional body regulating the profession could be seen as the strength, with opportunities of existing training and curriculum of the dental courses can positively have impact on dental healthcare delivery system in the Nigeria. On the other hands, weakness of the profession for now is non availability of constant power supply to operate the laboratory equipment and appliance, lack enactment of government policies and regulations on dental healthcare delivery system. Then, unfortunately, the threat facing the dental laboratories and the dental healthcare systems in the country can be quack workers obsolete equipment, dependency on foreign equipments and importation of materials and low patronage due perception of people on dental healthcare

From the results obtained and displayed in tables above the respondents do aware of the importance of laboratory managements towards the dental health delivery systems within the healthcare delivery system. Poor maintenance of the equipments, poor handily of the equipments and proper supply of materials can affect the operation of dental laboratory services.

The two hypotheses put forward for the study were all rejected for instance hypothesis one that the statuses of the laboratory facilities will not significantly influence dental healthcare delivery system. Then, the management of the laboratory will not significantly influence dental healthcare delivery system. The perception of the respondents of the strength, weakness, opportunities and threat (SWOT) of the dental laboratory showed that dental healthcare delivery system can be improved through giving support for training of staff with strong council to regulate the activities of dental health practitioners, and working against the (threat) quack workers in the profession, and provision of power supply to run appliances and equipments. Furthermore, with government supports, the dental healthcare delivery system can be improved through the activities of dental laboratories.

\section{Conclusion and Recommendations}

The study showed that the laboratory equipments are fairly in good conditions and they require more improvement and acquisitions of modern digital ones that will attract the patients, build confidences. The perception of the workers indicated that the condition and management of laboratory influence the effectiveness of dental services and improvement of dental healthcare delivery system. However, from the SWOT analysis showed that the strengths and opportunities of the facilities and situation is less than the threat and weakness. But the threat and 
weakness should be taken care of to prevent any further deterioration of the facilities and the patients and the professionals can be encouraged.

Based on the outcome of the study, the following recommendations were put forward:

(a) There is need for organization of more workshops, conferences on need to improved dental laboratories and educate the professionals on the latest equipment in the markets on a global level. Then, the Government should embark on infrastructural development of the existing governmental dental facilities and encourage the private ones.

(b) There is need for more improvement of the equipments and tools, and use of modern and digital equipments, and

(c) Equipping the workers with training and re-training through workshop, seminar and conference attendance on latest practices, new discovery and equipments at global level.

(d) For the development and proper management of dental technology, the staff, all cadres both technology and clinical dentistry should interaction positively and have understanding with those in their counterpart profession to promote healthcare delivery system.

\section{REFERENCES}

'A new oral health care system' (2006) Dental Abstracts, 51(3).

'Dental Care Delivery System' (2008) Encyclopedia of Public Health. Springer.

'Healthcare Information System' (2008) Encyclopaedia of Public Health. Springer.

'Laboratory Reference Values' (2009) Medicine for Dental Students.

Bailit, H. (1990) 'Dental Informatics: An Overview', Lecture Notes in Medical Informatics.

Balenseifen, J. W. and Madonia, J. V. (1970) 'Study of Dental Plaque in Orthodontic Patients', Journal of Dental Research, 49(2).

BS, M. (2013) 'Chapter-16 Functions of Teeth', Textbook of Dental Anatomy and Oral Physiology.

C. G Loiselle,. J Profetto-McGrath,.,D.F Polit,, \& C.T Beck, C.T.: Canadian essentials of nursing research. First Edition. New York: Lippincott, Williams \& Wilkins. Peer reviewed. $537 \mathrm{p}$

Community Tool Box (2014) SWOT Analysis: Strengths, Weaknesses, Opportunities, and Threats Work Group for Community Health and Development at the University of Kansas

Cousin, G. C. S. (1997) 'Facial nerve palsy complicating dental surgery', British Journal of Oral and Maxillofacial Surgery, 35(3).

Dean, C. (2009) 'Dental Tissues: An Introduction', Frontiers of Oral Biology.

Dubner, R., Sessle, B. and Storey, A. (1978) 'Mastication', The Neural Basis of Oral and Facial Function. Springer.

Durham, J. (2012) 'Acute Presentations of Chronic Oro-Facial Pain Conditions', Greenwood/Dental Emergencies.

Ghimire, N. (2013) ‘Oral Health-An Integral Part of General Health',Journal of Mass Communication \&amp; Journalism, 03.

Harris, R. (1973) 'THE DENTAL LABORATORY TECHNICIAN',Australian Dental Journal, 18(5-6).

Heffron, W. (1973) 'The dental laboratory technician. His role and training', Australian Dental Journal, 18(5-6).

http://ctb.ku.edu/en/table-of-contents/assessment/assessing-community-needs-and-resources/swot-analysis/main

http:/ / www.lagosstate.gov.ng/pagelinks.php?p=6

http://www.lawma.gov.ng/DataBank/LAWMA\%20Medical\%20Waste\%20Management\%20Unit.pdf

http:/ / www.onlinenigeria.com/links/lagosadv.asp?blurb=318\#ixzz3HCrR71Oy

K.H.T (1957) 'The dental treatment of maxillo-facial injuries', Oral Surgery, Oral Medicine, Oral Pathology, 10(4).

Kent, J., Homsy, C. and Hinds, E. (1975) 'Proplast in dental facial reconstruction', Oral Surgery, Oral Medicine, Oral Pathology, 39(3).

Kieffer, J. and Hoogstraten, J. (2008) 'Linking oral health, general health, and quality of life', European Journal of Oral Sciences, 116(5).

Lagos State Bureau of Statistics 2005.

LAWMA (2014) Statistics of Healthcare Facilities in Lagos State

Moen, D. and Meredith, L. (2010) 'Active Management of Healthcare Operations: A Dynamic System View of Healthcare Delivery', Journal of Medical Devices, 4(2).

Nelson, A. (1990) 'Change in the healthcare delivery system', Journal of Continuing Education in the Health Professions, 10(2).

OnlineNigeria.com (2014) Background Information on Lagos State

Parashar, P., Terezides, A., Sarlani, E. and Nikitakis, N. G. (2005) ‘Dental follicular hamartomas in the opercula of teeth delayed in eruption', Oral Surgery, Oral Medicine, Oral Pathology, Oral Radiology, and Endodontology, 99(4).

Prosthetics, A. of D. (1959) 'Dentist and dental laboratory technician relations', The Journal of Prosthetic Dentistry, 9(5).

Rowell, G. (1963) 'The organization of the dental profession in Australia', Australian Dental Journal, 8(1).

Schlott, W. (2009) 'WORN TEETH', Journal of the American Dental Association, 140(4).

Seggie, J. (2012) 'Human resource challenges in healthcare delivery in African communities', African Journal of Health Professions Education, 4.

Tepper, L. (2008) 'Educating the Dental Profession', Improving Oral Health for the Elderly. Springer 